\title{
Multi-Stage Game of Knowledge Pricing
}

\author{
Liu Fen ${ }^{1}$, Zhang Zhigang ${ }^{2}$, Zhao Lutao ${ }^{*}$, Zhou Xiongfeng $^{2}$ and Xiang Meiyu ${ }^{2}$ \\ ${ }^{I}$ School of Automation and Electrical Engineering, University of Science and Technology Beijing, Beijing, 100083, P.R. \\ China \\ ${ }^{2}$ School of Mathematics and Physics, University of Science and Technology Beijing, Beijing, 100083, P.R. China
}

\begin{abstract}
Knowledge pricing is a game process between buyers and sellers. Firstly, through the analysis of multi-stage knowledge pricing, this paper reaches a conclusion that the knowledge pricing game for the first stage is an incomplete and perfect dynamic game and is a complete and perfect information dynamic game for the following stages. Secondly, this paper tries to build a knowledge-priced multi-stage game model for knowledge pricing, analyzing and studying a variety of situations. By using backward induction to solve the objective function, the paper obtains some pricing criteria for sellers when the knowledge quality is different and the rules for whether the buyers choose to buy this knowledge when the knowledge pricing is different.
\end{abstract}

Keywords: Knowledge pricing, Multistage game, Game theory.

\section{INTRODUCTION}

Recently, knowledge has surpassed the land, labor and capital, becoming the key resource and a new economic growth point. More and more enterprises recognized that it is important to ensure sustainable development and enhance enterprises' core competitiveness by using knowledge reasonably and keeping continual innovation.

Many domestic and foreign scholars have conducted researches on the knowledge pricing, which mainly started from cost, value and game theory [1]. Among foreign scholars, Reich measured the value of knowledge on the basis of two types of knowledge's definitions in 1994 [2]. In 2004, by means of products and work processes, Ahn assessed the contribution of knowledge to the business performance and measured the value of knowledge [3]. Among domestic scholars, Wang studied knowledge pricing from social labor and cost $[4,5]$, concluding the formula of knowledge pricing. Gao used present earning value method to measure the value of knowledge [6]. Chen introduced the concept of knowledge distance. By influencing the trust relationship between buyers and sellers and knowledge distance, he used game theory to study knowledge pricing respectively from the perspective of buyer and seller [7]. Liu constructed and analyzed the game model of intellectual property transaction, then pointed out that there are five possible game results between buyers and sellers in the non-repeated game of intellectual property transactions [8].

\footnotetext{
*Address correspondence to this author at the School of Mathematics and Physics, University of Science and Technology Beijing, Beijing, 100083, P.R. China; Tel: 13521776678; E-mail: allan_ke @163.com
}

After the study of von Neumann and Morgenstern [9] and Nash $[10,11]$, game theory rapidly became matured. Game theory plays an important role in decision support systems and decision sciences and involves in extensive subjects like psychology, quantum computing, voting, trade, AI, pricing and so on [12-17]. In real life, when buyers and sellers are trading knowledge, the transaction prices are the result of game. Essentially, the transaction of knowledge is a game under the premise of buyers and sellers which maximizes their own interests. In order to reduce the risk, sometimes buyers don't tend to buy the knowledge out at the first time. Purchasing it through several stages is safer. Hence, it is necessary to apply multi-stage game theory to knowledge pricing.

\section{MODELING MULTI-STAGE GAME OF KNOWLEDGE PRICING}

In the whole process of knowledge pricing, the trading activities can be regarded as a game in which participants are parties to the transaction. The entire transaction goes through quotation, concluding a transaction and other processes, which turn out to be a dynamic game. In the first pricing stage, the buyer merely knows the seller's bid, and the quality level of knowledge is unknown. While in the non-first stage, the buyer and seller know each other's decision strategies of former stages and then determine the quality of the knowledge based on the actual profit and bid of the former stages. Therefore, this model is incomplete information dynamic game in the first pricing stage and perfect information dynamic game in the non-first pricing stages. Assuming that the benefit brought by knowledge is constant in every stage, it can be further defined as totally perfect information dynamic game. 


\subsection{The Basic Assumption}

The model is constructed as below with the following assumptions:

(1) The transaction is successful or not only depends on the buyers and sellers involving in the game, regardless of other external factors.

(2) The types of knowledge only have two cases: high quality and low quality.

(3) In the first stage, the two kinds of future gain that buyers expect to generate in the two cases are $V_{g}$ and $V_{b}$ respectively and $V_{g}>V_{b}$; while in the non-first stages, let $V_{1}$ be the practical gain in the previous phase and $V_{g} \geq V_{1} \geq V_{b}$. The buyer determines the type of knowledge by comparing the expected gain and the actual gain.

(4) At the beginning of each stage, the seller make decision first, setting high price $P_{h}$ or low price $P_{l}$.

(5) The buyer can't bargain and the strategies are to buy or not to buy, which are denoted by $a_{1}$ and $a_{2}$.

(6) The efforts that sellers make to obtain high-quality and low-quality knowledge are recorded as $C_{g}$ and $C_{b}$, and the packaging cost is $C_{p}$ when the seller sets high price for low quality knowledge.

(7) $Q_{1}$ and $Q_{2}$ are the net gains that measure the benefit of buyers and sellers.

(8) For simplification, let $V_{g}-P_{h}>V_{b}-P_{l}>0>V_{b}-P_{h}$. The inequation means the benefit gained from buying the low quality knowledge with low price is smaller than that gained from buying the high quality knowledge with high price but it still does not achieve negative returns; while it is possible for buyers to earn negative profit if paying a high cost to buy low quality knowledge. As the buyer, to purchase high quality knowledge with a low price will get the highest profit, but in this situation there is the possibility that knowledge is undervalued or existing related to party transactions market or benefits transferred.

\subsection{Process Analysis of Multi-Stage Game}

(1) The first pricing stage

In the first phase, nature selects the type of knowledge. The type set of knowledge is $\theta=\{g, b\}$, where $g$ represents the high-quality knowledge and $b$ represents the low-quality knowledge. Let $p(g)$ and $p(b)$ represent the priori probability of knowledge that are high-quality or low-quality respectively, where $0 \leq p(g), p(b) \leq 1$ and $p(g)+p(b)=1$.

In the second phase, seller selects price $p \in P=\{h, l\}$ according to the type of knowledge, where $h$ stands for high price and $l$ stands for low price.
In the third phase, the buyer does not know the type of knowledge, but knows the probability distribution of the type of knowledge $p(\theta)$ and draws on the posterior probability of the quality of knowledge $p(\theta \mid P)$ through the price $P$ given by the seller, then decides to buy or not. Due to that the seller's price can be high or low in case of any quality of knowledge. The buyer can not only determine the level of quality of knowledge by the seller's bid, but also still needs to collect additional information (assume that the posterior probability is available by market research and the buyer selects an action from the set $A=\left\{a_{1}, a_{2}\right\}$ according to this posterior probability).

The above processes are shown in the game tree in Fig. (1). At the brackets, the upper formulas denote the seller's benefit, and the below denote the buyer's benefit (the same in Fig. (2)).

Based on the above analysis, the expectations benefit of the buyer in the first stage is:

$$
\begin{aligned}
E(V)= & p(g \mid h)\left(V_{g}-P_{h}\right)+p(b \mid h)\left(V_{b}-P_{h}\right) \\
& +p(g \mid l)\left(V_{g}-P_{l}\right)+p(b \mid l)\left(V_{h}-P_{l}\right)
\end{aligned}
$$

The above four probabilities in sequence are the conditional probabilities of high price given to the high-quality knowledge, high price given to the low-quality knowledge, low price given to the high-quality knowledge and low price given to the low-quality knowledge.

(2) The non-first pricing stages

The situation of the first two phases is similar to the first stage. In the third phase, the buyer knows that knowledge can bring gains $V_{1}$. If $V_{1}>\left(V_{g}+V_{b}\right) / 2$, then the buyer considers that the knowledge is high-quality knowledge. If $V_{1} \leq\left(V_{g}+V_{b}\right) / 2$, then the buyer believes that the knowledge is low-quality knowledge. Consequently, the buyer will correct posterior probability $p(\theta \mid P)$ through the type of the knowledge quality and select an action from the action set $A=\left\{a_{1}, a_{2}\right\}$ according to this probability.

Similarly, the above process can be shown in Fig. (2), the expectations benefit of the buyer in the non-first stages is:

$$
\begin{aligned}
E(V)= & p(g \mid h)\left(V_{1}-P_{h}\right)+p(b \mid h)\left(V_{1}-P_{h}\right) \\
& +p(g \mid l)\left(V_{1}-P_{l}\right)+p(b \mid l)\left(V_{1}-P_{l}\right)
\end{aligned}
$$

\section{ANALYZING AND SOLVING MULTI-STAGE GAME OF KNOWLEDGE PRICING}

\subsection{Analysis of the Buyer}

(1) The first pricing

After the seller set high price, the buyer's action is to meet the following optimization model: 


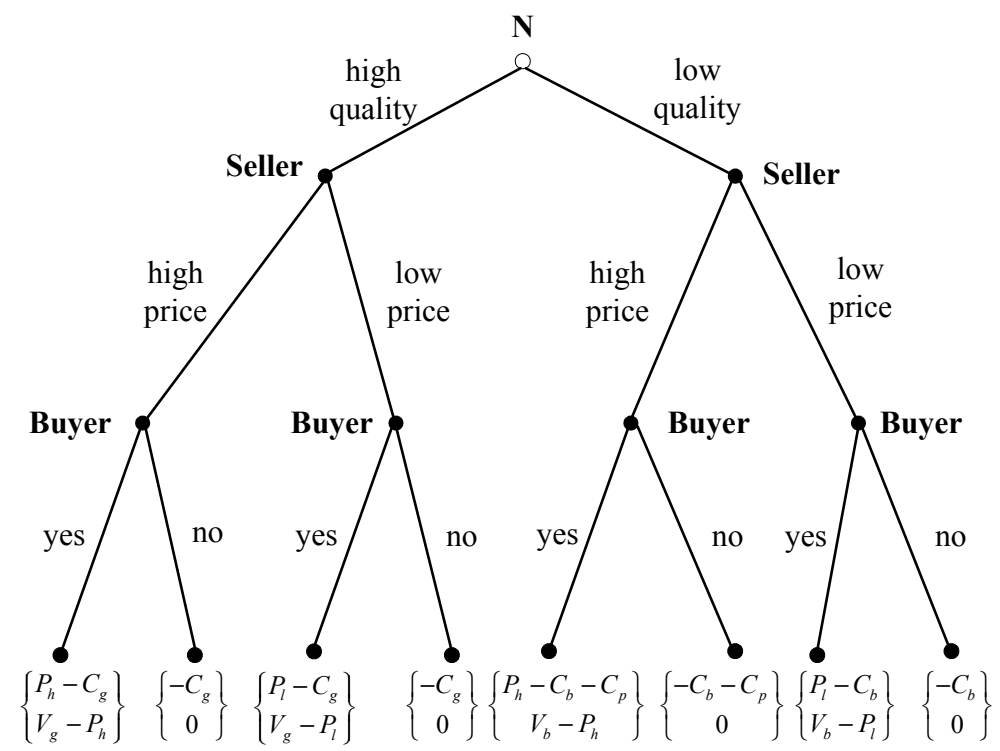

Fig. (1). Game analysis for the first pricing stage.

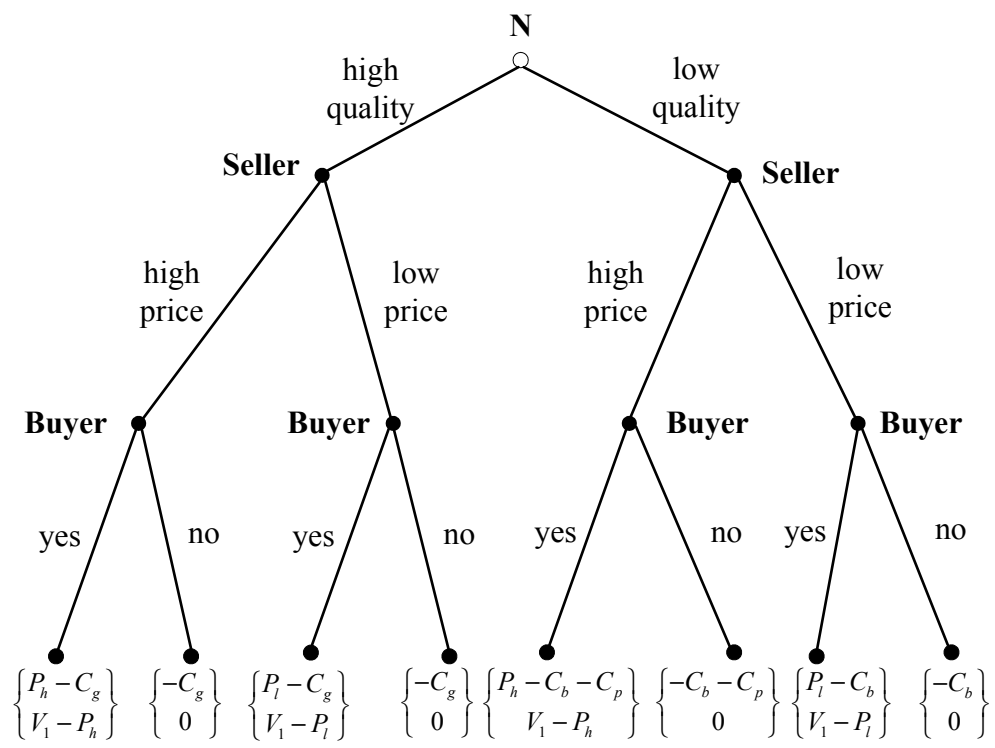

Fig. (2). Game analysis for the non-first pricing stages.

$E(V)=\max \left\{p(g \mid h)\left(V_{g}-P_{h}\right)+p(b \mid h)\left(V_{b}-P_{h}\right), 0\right\}$

s.t. $\left\{\begin{array}{c}p(g)+p(b)=1 \\ V_{g}-P_{h}>0 \\ V_{b}-P_{h}<0 \\ 0 \leq p(b \mid h) \leq 1 \\ 0 \leq p(g \mid h) \leq 1\end{array}\right.$

When $E(V) \geq 0$, the buyer chooses to buy; when $E(V)<0$, the buyer chooses not to buy.

Now discuss and analyze these two cases:
$E(V) \geq 0$ means $p(g \mid h)\left(V_{g}-P_{h}\right)+p(b \mid h)\left(V_{b}-P_{h}\right) \geq 0$. It can be modified as the following by the constraint conditions:

$\frac{p(g \mid h)}{p(b \mid h)} \geq \frac{P_{h}-V_{b}}{V_{g}-P_{h}}$

That is when formula (4) is met, the buyer's expected gain is not negative. Move $P_{h}$ to the right hand of the inequality sign, then

$$
P_{h} \leq \frac{p(g \mid h) V_{g}+p(b \mid h) V_{b}}{p(b \mid h)+p(g \mid h)}
$$


When $E(V)<0$, in the similar way we can get:

$$
P_{h}>\frac{p(g \mid h) V_{g}+p(b \mid h) V_{b}}{p(b \mid h)+p(g \mid h)}
$$

That means in the first pricing game, if the seller set a high price, the buyer will consider whether the pricing meets $P_{h} \leq \frac{p(g \mid h) V_{g}+p(b \mid h) V_{b}}{p(b \mid h)+p(g \mid h)}$. If it does, the buyer would decide to buy the knowledge, otherwise chooses not to buy.

After the seller sets low price, the buyer's action needs to meet the following model:

$E(V)=\max \left\{p(g \mid l)\left(V_{g}-P_{l}\right)+p(b \mid l)\left(V_{b}-P_{l}\right), 0\right\}$

$$
\text { s.t. }\left\{\begin{array}{c}
p(g)+p(b)=1 \\
V_{g}-P_{l}>0 \\
V_{b}-P_{l}>0 \\
0 \leq p(b \mid l) \leq 1 \\
0 \leq p(g \mid l) \leq 1
\end{array}\right.
$$

When $E(V) \geq 0$, the buyer chooses to buy; when $E(V)<0$, the buyer chooses not to buy.

According to $0 \leq p(g / l) \leq 1$ and $V_{g}-P_{l}>0$, we can get $p(g \mid l)\left(V_{g}-P_{l}\right) \geq 0$ and $p(b \mid l)\left(V_{b}-P_{l}\right) \geq 0$, therefore $p(g \mid l)\left(V_{g}-P_{l}\right)+p(b \mid l)\left(V_{b}-P_{l}\right) \geq 0$, that is to say $E(V) \geq 0$. Hence in the first pricing stage, if the seller chooses low price, the buyer would choose to buy the knowledge regardless of the quality of knowledge.

(2) The non-first pricing

Different from the first pricing stage, in non-first pricing stages the expected gain can be simplified through comparing $V_{1}$ with $\left(V_{g}+V_{b}\right) / 2$.

When the seller sets high price, the buyer's choice should satisfy

$$
E(V)=\max \left\{p(g \mid h)\left(V_{1}-P_{h}\right)+p(b \mid h)\left(V_{1}-P_{h}\right), 0\right\}
$$

When $V_{1}>\left(V_{g}+V_{b}\right) / 2$, the knowledge is high quality. That is $p(g \mid h)=1, p(b \mid h)=0$, therefore, $E(V)=V_{1}-P_{h}$. According to assumptions that high-quality knowledge given the high price would not get a negative benefit, we can see that $V_{1}-P_{h} \geq 0$, hence $E(V)>0$. Similarly, $V_{1}-P_{h}<0$, so $E(V)<0$. It is concluded that in the non-first pricing game, if the seller choses high price, the buyer judges the quality type of knowledge by $V_{1}$. If $V_{1}>\left(V_{g}+V_{b}\right) / 2$, the knowledge is high-quality, the buyer chooses to buy, otherwise not to buy.

When the seller sets low price, the buyer's choice should meet

$$
E(V)=\max \left\{p(g \mid l)\left(V_{1}-P_{l}\right)+p(b \mid l)\left(V_{1}-P_{l}\right), 0\right\}
$$

Similarly, when $V_{1}>\left(V_{g}+V_{b}\right) / 2, p(g \mid l)=1, p(b \mid l)=0$, then $E(V)=V_{1}-P_{l} \geq 0$. When $V_{1} \leq\left(V_{g}+V_{b}\right) / 2$, $p(g \mid l)=0, p(b \mid l)=1$, then $E(V)=V_{1}-P_{l}>0$. It is concluded that in the non-first pricing game, if the seller sets low price, the buyer chooses to buy.

\subsection{Analysis of the Seller}

To simply the analysis, it can be assumed that when the seller sets high price, probability of the buyer choosing to purchase the knowledge is $p\left(a_{1} \mid h\right)=\frac{p(g \mid h)}{p(g \mid h)+p(b \mid h)}$, not to purchase is $p\left(a_{2} \mid h\right)=\frac{p(b \mid h)}{p(g \mid h)+p(b \mid h)}$; when the seller sets low price, probability of the buyer choosing to purchase is $p\left(a_{1} \mid h\right)=1$, not to purchase is $p\left(a_{2} \mid h\right)=0$.

Factors that affect the seller's pricing the knowledge have not changed no matter in the first pricing stage or nonfirst pricing stages. That is the game model for the seller does not change. Therefore, there is no need to analyze the cases in first or non-first stage respectively. It only needs to analyze the cases with different types of knowledge quality.

\section{(1) High-quality knowledge}

According to the above analysis, the goal of the seller's decision is to satisfy:

$$
\begin{aligned}
& Z=\max \left\{p\left(a_{1} \mid h\right)\left(P_{h}-C_{g}\right)-p\left(a_{2} \mid h\right) C_{g},\right. \\
& \left.p\left(a_{1} \mid l\right)\left(P_{l}-C_{g}\right)-p\left(a_{2} \mid l\right) C_{g}\right\} \\
& \text { s.t. }\left\{\begin{array}{l}
p\left(a_{1} \mid h\right)+p\left(a_{2} \mid h\right)=1 \\
p\left(a_{1} \mid l\right)=1 \\
p\left(a_{2} \mid l\right)=0 \\
P_{h}>P_{l}>0
\end{array}\right.
\end{aligned}
$$

According to the constraint conditions, the objective function can be simplified into:

$$
Z=\max \left\{p\left(a_{1} \mid h\right) P_{h}-C_{b}-C_{p}, P_{l}-C_{b}\right\}
$$

When $p\left(a_{1} \mid h\right) P_{h}-C_{b}-C_{p}>P_{l}-C_{b}$, that is to say $p\left(a_{1} \mid h\right)>\left(P_{l}+C_{p}\right) / P_{h}$, the seller chooses to set high price, otherwise, the seller chooses to set low price.

(2) Low-quality knowledge

Similarly, the goal of the seller's decision is to satisfy

$$
\begin{aligned}
Z=\max \{ & p\left(a_{1} \mid h\right)\left(P_{h}-C_{b}-C_{p}\right)-p\left(a_{2} \mid h\right)\left(C_{b}+C_{p}\right), \\
& \left.p\left(a_{1} \mid l\right)\left(P_{l}-C_{b}\right)-p\left(a_{2} \mid l\right) C_{b}\right\}
\end{aligned}
$$


s.t. $\left\{\begin{array}{l}p\left(a_{2} / h\right)=1-p\left(a_{1} / h\right) \\ p\left(a_{1} / l\right)=1 \\ p\left(a_{2} / l\right)=0 \\ P_{h}>P_{l}>0\end{array}\right.$

According to the constraint conditions, the objective function can be simplified into:

$Z=\max \left\{p\left(a_{1} \mid h\right) P_{h}-C_{b}-C_{p}, P_{l}-C_{b}\right\}$

When $p\left(a_{1} \mid h\right) P_{h}-C_{b}-C_{p}>P_{l}-C_{b}$, that is to say $p\left(a_{1} \mid h\right)>\left(P_{l}+C_{p}\right) / P_{h}$, the seller chooses to set high price, otherwise, the seller chooses to set low price.

\section{CONCLUSION}

Through the establishment and analysis of a multi-stage game of knowledge pricing model, after giving the seller's pricing and the buyer's standard of decision, we can conclude the buyer's decision criteria as follows. In the first pricing stage, if the seller chooses high price, the buyer chooses to buy the knowledge according to $P_{h} \leq \frac{p(g \mid h) V_{g}+p(b \mid h) V_{b}}{p(b \mid h)+p(g \mid h)}$, otherwise chooses not to purchase it; if the seller sets low price, the buyer purchases the knowledge in any case. In the non-first pricing stage, if the seller sets high price, the buyer would determine about the quality of the knowledge by $V_{1}>\left(V_{g}+V_{b}\right) / 2$; if the seller sets low price, the buyer would buy it in any case.

In the paper, we also analyzed the seller's pricing strategies. If the knowledge is high-quality, when the probability of the buyer purchasing it with a high price is $p\left(a_{1} \mid h\right)>P_{l} / P_{h}$, the seller will choose high price, whereas the seller chooses low price. If the knowledge is low-quality, when the probability of the buyer purchasing it with high price is $p\left(a_{1} \mid h\right)>\left(P_{l}+C_{p}\right) / P_{h}$, then the seller will choose high price, whereas the seller chooses low price.

This paper's conclusions have a certain degree of theoretical guidance on improving the market of knowledge and promoting knowledge trade.
The authors confirm that this article content has no conflict of interest.

\section{ACKNOWLEDGEMENTS}

The authors gratefully acknowledge the financial support from Beijing Higher Education Young Elite Teacher Project (YETP0386) and Project 71403014 supported by National Natural Science Foundation of China.

\section{REFERENCES}

[1] H. -S. Ji, and Q. Lu, "Knowledge transaction and the model of knowledge pricing", Journal of East China University of Science and Technology, pp 53-57, 65, 2010.

[2] Y. Reich, "Measuring the value of knowledge", International Journal of Human-Computer Studies, vol. 42, pp. 3-30, 1995.

[3] J. H. Ahn, and S. -G. Chang, "Assessing the contribution of knowledge to business performance: the $\mathrm{KP}^{3}$ methodology", Decision Support Systems, vol. 36, pp. 403-416, 2004.

[4] C. -Q. Wang, "Knowledge pricing", Studies in Dialectics of Nature, vol. 14, pp. 52-53, 1998 .

[5] C. -Q. Wang, "On the pricing of the general cost of knowledge", Studies in Science of Science, vol. 17, pp. 25-30, 1999.

[6] X. -Y. Gao, and S. -G. Zou, "Ideals on measurement of knowledge", Studies in Dialectics of Nature, vol. 16, pp. 54-57, 72, 2000.

[7] B. Chen, "Distance of knowledge and pricing knowledge", Studies in Science of Science, vol. 25, pp. 14-18, 2007.

[8] W. -G. Liu, and Q. -W. Li, "Game analysis on deal pricing of enterprise intellectual property rights", Statistics and Decision, pp. 60-62, 2010

[9] J. V. Neumann, and O. Morgenstern, Theory of Games and Economic Behavior, Princeton University Press, Princeton, 1953.

[10] J. F. Nash, "Equilibrium points in n-person games", Proceedings of the National Academy of Sciences of the USA, vol. 36, pp. 48-49, 1950 .

[11] J. F. Nash, "Noncooperative games", Annals of Mathematics, vol. 54, pp. 286-295, 1951

[12] M. Dufwenberg, S. Gächter, and H. Hennig-Schmidt, "The framing of games and the psychology of play", Games and Economic Behavior, vol. 73, pp. 459-478, 2011.

[13] H. Guo, J. -h. Zhang, and G. J. Koehler, "A survey of quantum games", Decision Support Systems, vol. 46, pp. 318-332, Dec. 2008.

[14] J. Freixas, B. Tchantcho, and N. Tedjeugang, "Voting games with abstention: linking completeness and weightedness", Decision Support Systems, vol. 57, pp. 172-177, 2014.

[15] P. M. Markopoulos, R. Aron, and L. Ungar, "Information markets for product attributes: a game theoretic, dual pricing mechanism", Decision Support Systems, vol. 49, pp. 187-199, May 2010.

[16] J. A. Brander, "Intra-industry trade in identical commodities", Journal of International Economics, vol. 11, pp. 1-14, 1981.

[17] J. Brynielsson, "Using AI and games for decision support in command and control", Decision Support Systems, vol. 43, pp. 1454 1463, Aug. 2007.

\section{CONFLICT OF INTEREST}

Received: September 16, 2014

Revised: December 23,2014

Accepted: December 31, 2014

(C) Fen et al.; Licensee Bentham Open.

This is an open access article licensed under the terms of the Creative Commons Attribution Non-Commercial License (http://creativecommons.org/licenses/by$\mathrm{nc} / 4.0 /$ ) which permits unrestricted, non-commercial use, distribution and reproduction in any medium, provided the work is properly cited. 